\title{
Cross-shore gradients of physical disturbance in mangroves: implications for seedling establishment
}

\author{
T. Balke ${ }^{1,2}$, T. J. Bouma ${ }^{1,3}$, P. M. J. Herman ${ }^{3}$, E. M. Horstman ${ }^{4}$, C. Sudtongkong ${ }^{5}$, and E. L. Webb ${ }^{6}$ \\ ${ }^{1}$ Marine and Coastal Systems, Deltares, P.O. Box, 177, 2600 MH Delft, the Netherlands \\ ${ }^{2}$ Singapore-Delft Water Alliance, No 1 Engineering Drive 2, National University of Singapore, Singapore 117576, Singapore \\ ${ }^{3}$ Royal Netherlands Institute for Sea Research (NIOZ-Yerseke), P.O. Box 140, 4400 AC Yerseke, the Netherlands \\ ${ }^{4}$ Department of Water Engineering \& Management, University of Twente, P.O. Box 217, 7500 AE Enschede, the Netherlands \\ ${ }^{5}$ Department of Marine Science, Rajamangala University of Technology Srivijaya, Sikao, Trang Province 92150, Thailand \\ ${ }^{6}$ Department of Biological Sciences, National University of Singapore, 14 Science Drive 4, Singapore 117543, Singapore
}

Correspondence to: T. Balke (thorsten.balke@deltares.nl)

Received: 26 November 2012 - Published in Biogeosciences Discuss.: 19 March 2013

Revised: 21 June 2013 - Accepted: 7 July 2013 - Published: 13 August 2013

\begin{abstract}
Mangroves may grow in an active sedimentary environment and are therefore closely linked to physical coastal processes. Seedlings colonize dynamic tidal flats, after which mangroves have the potential to change their physical environment by attenuating hydrodynamic energy and trapping sediments. Disturbance from hydrodynamic energy of waves or currents and the resulting sediment dynamics appear to be a critical bottleneck for seedling establishment on tidal flats and at the forest fringe. However, knowledge about the mechanisms at the single plant level and the spatial pattern of disturbance is limited. By means of a flume study, we demonstrate that a surface erosion threshold of as little as $1-3 \mathrm{~cm}$ depth can lead to failure of young seedlings. By monitoring accretion/erosion for 8 months along cross-shore transects in southwest Thailand, we show that, especially on the bare mudflat, the physical sediment disturbance regularly exceeds the critical erosion thresholds derived from the flume study. Physical sediment parameters along the same transects were analysed to deduct patterns of hydrodynamic energy attenuation. Grain size analysis and erosion/accretion data showed only limited energy dissipation within the fringing Avicennia/Sonneratia zone; sediment dynamics only dropped below lethal values for seedlings within the denser Rhizophora zone. Overall, present results emphasize that (i) seedling survival is extremely sensitive to physically driven sediment dynamics and (ii) that such physical disturbances are not only present on the tidal flats but can penetrate a significant distance into the forest. Spatio-temporal patterns in sediment dynamics should hence be considered when conducting restoration of mangrove ecosystems.
\end{abstract}

\section{Introduction}

Coastal development and mangrove deforestation have significantly reduced global mangrove area and created a need for restoration (FAO, 2007). In order to restore degraded mangrove systems, a complete understanding of the processes that lead to natural changes in mangrove area is necessary. Mangroves are bio-geomorphic ecosystems that are strongly affected by coastal sediment dynamics. Newly accreted tidal flats may get rapidly colonized by mangrove pioneers, whereas coastal erosion can cause lateral retreat of mangrove vegetation (see e.g. Panapitukkul et al., 1998; Thampanya et al., 2006; Anthony et al., 2010). Mangroves predominantly occur along sheltered coastlines (Tomlinson, 1986). Nevertheless, even at those areas physical disturbance such as short periods of increased wave heights or current velocities, sediment deposition, or erosion can inhibit seedling establishment (see e.g. Balke et al., 2011; Thampanya et al., 2002) and influence the forest structure (Lovelock et al., 2010). Understanding barriers to mangrove establishment may be particularly important at sites where mangroves have a coastal protection function. Despite the general importance to understand seedling survival of mangrove pioneer species in a dynamic coastal setting, this knowledge gap has yet to be filled (reviewed in Friess et al., 2012).

Seedling establishment in mangroves has been studied in relation to various factors such as salinity (e.g. Ball and Pidsley, 1995), inundation stress (e.g. Ashford and Allaway, 1995), predation on propagules or seedlings (e.g. McKee, 1995), pre-dispersal frugivory (e.g. Minchinton and 
Dalby-Ball, 2001), tidal flat elevation and morphology (Proisy et al., 2009) as well as soil chemistry, temperature, light, and $\mathrm{CO}_{2}$ (reviewed in Krauss et al., 2008). Publications on physical disturbance in mangroves are mainly focused on large infrequent disturbances, such as tsunamis (Alongi, 2008), hurricanes or lightning (Smith et al., 1994). The few studies on seedling mortality of mangrove pioneer species, due to frequent small physical disturbances of the sediment bed, are scanty and mainly focused on high rates of sedimentation (Terrados et al., 1997; Thampanya et al., 2002).

In SE Asia, the pioneer species Avicennia alba and Sonneratia alba are the first to colonize a mudflat and/or are found in the lower and most dynamic portion of the intertidal zone (Tomlinson, 1986, reviewed in Friess et al., 2012). A. alba develops (crypto-) viviparous propagules, whereas $S$. alba produces fruits containing many woody seeds. Buoyant propagules of Avicennia alba require a disturbance-free period to anchor against subsequent flooding and drag forces by water movement (Balke et al., 2011). Once propagules are anchored, short-term erosion can still dislodge them (Balke et al., 2011) and excessive sedimentation can kill even several-month old seedlings of both species due to burial (Thampanya et al., 2002). Burial by sediment, as may occur after major storm events (Paling et al., 2008), can also affect mature mangrove trees when the pneumatophores are covered and oxygen becomes limiting for the trees (reviewed in Ellison, 1999).

Most of the studies on burial of seedlings and saplings have focused on one-time experimental sediment burial in the field. For example, Terrados et al. (1997) concluded that areas with sudden sedimentation of $>4 \mathrm{~cm}$ on top of the tidal flat are not suitable for Rhizophora apiculata seedling establishment. compared survival of three species after a single burial event. Whereas mortality of Sonneratia caseolaris and Avicennia officinalis seedlings was significantly increased by different rates of burial, Rhizophora mucronata showed no significant response to variable burial rates, although natural mortality was higher compared to the most successful Sonneratia caseolaris.

The effect of short-term erosive events on seedling survival has gained much less attention than burial, although exposure to hydrodynamics and concomitant surface sediment mixing (i.e. alternation of erosion and accretion) has been mentioned as a reason for failure of restoration efforts (see Lewis III, 2005). Other than a single flume study on propagule dislodgement of Avicennia sp. (Balke et al., 2011) and a single mesocosm study on the cumulative effects of accretion and erosion around seedlings for Avicennia and Sonneratia (Balke et al., 2013), to our knowledge no study has experimentally quantified the erosion limits of recently established mangrove seedlings and linked this to field observations on actual surface sediment dynamics.

In addition to the need to further quantify the response of seedlings to physical sediment disturbance, it is equally critical to quantify the spatial distribution of such disturbances at the sediment bed across the intertidal zone (i.e. going from bare tidal flat to the back of the mangrove forest). In general, hydrodynamic energy (waves and currents) is attenuated from the mudflat to the back mangrove (Mazda et al., 2006; Quartel et al., 2007) due to the above-ground tree structures and decreasing water depth, so that surface sediment mixing (i.e. erosive forces) is similarly reduced (Smoak and Patchineelam, 1999). The attenuation of energy is evident from decreasing sediment grain sizes from the forest edge towards the back of the mangrove forest (Saad et al., 1999). Sediment coring studies with ${ }^{210} \mathrm{~Pb}$ have estimated mixing depths in front of a mangrove of maximum $25 \mathrm{~cm}$ in New Zealand (Swales et al., 2007) and $30 \mathrm{~cm}$ in Brazil (Smoak and Patchineelam, 1999), which would far exceed critical survival thresholds (Balke et al., 2011, 2013). These coring studies do however not provide insight into the frequency and spatial pattern of this sediment mixing. In order to obtain a more general insight into the short-term physical disturbance pattern critical for seedling survival/mortality, there is a need to frequently monitor the sediment dynamics across transects.

In this study, we combine flume experiments to quantify seedling erosion thresholds with field monitoring of smallscale sediment disturbances along transects in Thai mangroves (Fig. 1). The combination of these measurements enables us to elucidate the spatial pattern of physical disturbance relevant for seedling survival. We quantified critical erosion thresholds for young seedlings of the common pioneer species Sonneratia alba through a flume experiment to gain insight into the mechanisms that lead to establishment failure. We analysed the spatial pattern of surface sediment mixing by using shallow marker plates over an 8-month period along cross-shore transects from the tidal flats towards the back of the forest in a Thai mangrove ecosystem. Physical sediment parameters were analysed across the same transects to conclude about attenuation of hydrodynamic energy. We aim at increasing current understanding of mangroves as a bio-geomorphic ecosystem, where lateral change at the forest fringe is largely determined by sediment dynamics and hydrodynamics.

\section{Methods}

\subsection{Flume experiments: establishing critical erosion thresholds for seedlings}

A wave flume of $38 \mathrm{~m}$ length and $0.9 \mathrm{~m}$ width at the National University of Singapore was filled with $30 \mathrm{~cm}$ freshwater and prepared with a test section in the middle of the flume, containing a second bottom with a hole to insert a $15 \mathrm{~cm}$-long and $12 \mathrm{~cm}$-diameter PVC pipe flush with the bed. Within these PVC pipes we placed mangrove seedlings experiencing different levels of erosion. To grow mangrove seedlings for the experiment, Sonneratia alba fruits were 

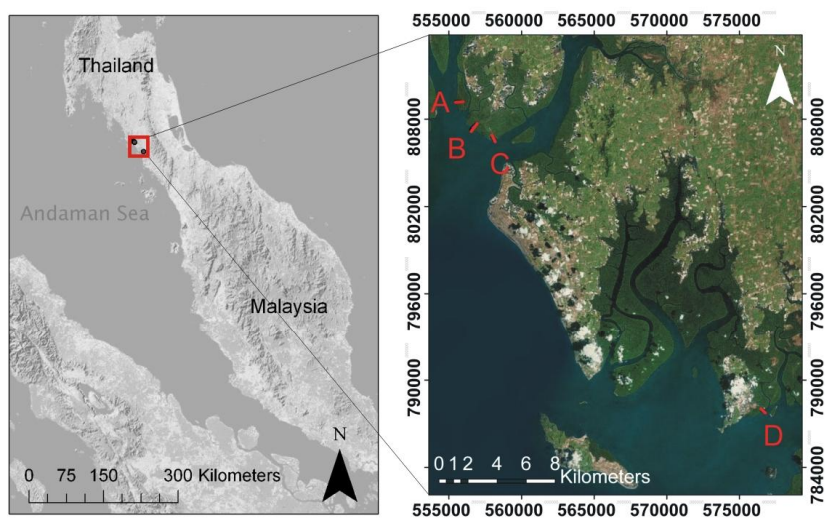

Fig. 1. Field sites in SW Thailand in the province of Trang. Four transects were laid out from the tidal flat towards the back of the mangrove forest (A-D) to measure surface sediment mixing. Regional map and aerial photograph from ArcGIS basemaps/Bing. Singapore is located at the southern tip of the Malay Peninsula.

collected from the Mandai mangrove forest and mangrove mud was collected from the mudflat surface at Sungei Buloh, Singapore. Sonneratia alba seeds were germinated in trays with mangrove mud and transplanted to the experimental pots (i.e. open PVC pipes, lined with plastic bags) and filled with mangrove mud to the rim. Seedlings were kept in the pots for several days until the start of the experiment, and sediment was kept waterlogged throughout. Seedling height varied between 2.7 and $6.7 \mathrm{~cm}(N=35)$ at the time of the erosion experiment. By inserting discs at the bottom of the PVC pipe, the plastic bag including mud and seedling could be pushed up above the rim and excess sediment could gently be scraped away to mimic erosion without destroying the roots (Fig. 2, left photo). Erosion was applied stepwise by $3 \mathrm{~mm}$ each run; thereafter the seedlings were exposed to typical waves (measured in the field, Horstman et al., 2012) with $8 \mathrm{~cm}$ wave height $(0.5 \mathrm{~Hz})$ in the flume tank for $150 \mathrm{sec}-$ onds. If the seedling did not topple, the erosion treatment was repeated and the seedling put back in to the flume for the next wave run. The short duration of the repeated exposure to waves did not affect the seedling stability or stiffness. Upon toppling of the seedling the number of discs was recorded as critical erosion depth and the seedling was gently removed from the soil. Each entire seedling was measured, oven dried $\left(48 \mathrm{~h}, 80^{\circ} \mathrm{C}\right)$ and weighed for dry biomass. All seedlings were grown from seed and possessed 1 to 4 leaf pairs, which were included for dry biomass.

\subsection{Field sites: transects for marker plates and sediment properties}

The Andaman coast of Trang province, southern Thailand, is characterized by mangroves and seagrass beds with one of the largest populations of the threatened Dugong in Thailand (Hines et al., 2005). The rainy season is usually from May to
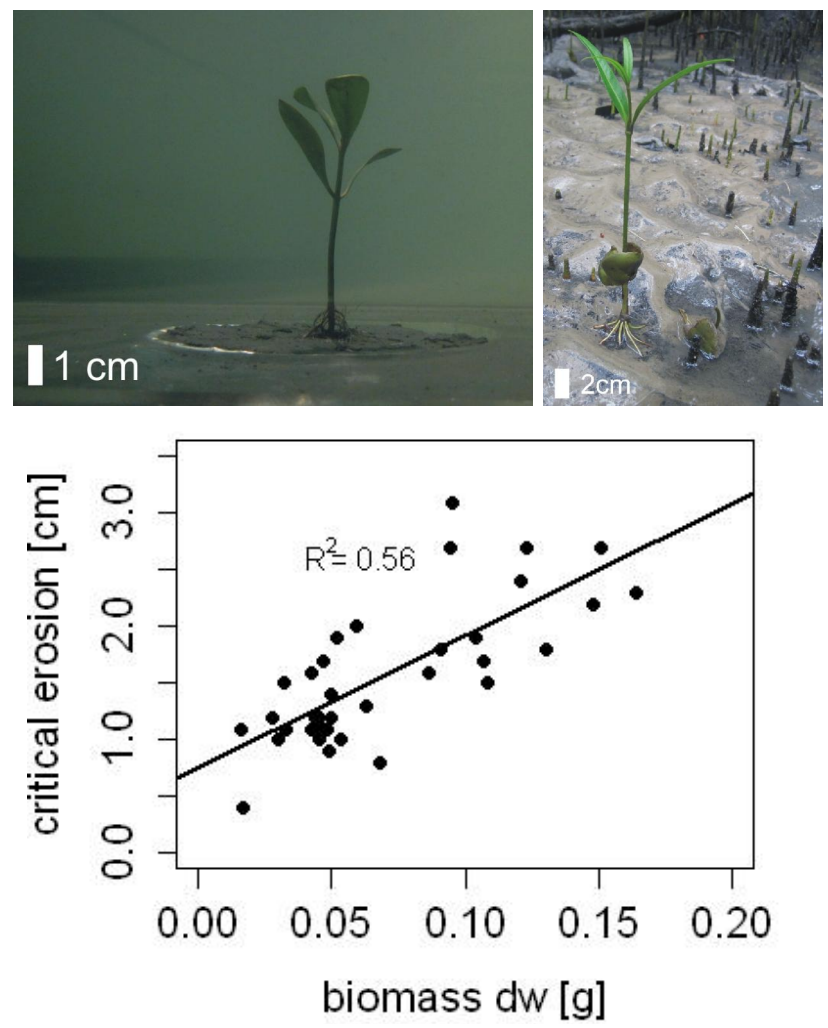

Fig. 2. Results of wave flume experiments on critical erosion depth for Sonneratia alba seedlings (left photo: $S$. alba in the flume) and photo of Avicennia sp. seedling showing exposed roots due to local erosion (right). Critical erosion depth $\left(E_{\text {crit }}\right)$ was linearly correlated with dry biomass of the seedlings $\left(B_{\mathrm{dw}}\right)$; $\left[E_{\text {crit }}=11.678 \cdot B_{\mathrm{dw}}+0.7493\right]$.

October/December. We selected two estuaries for this study (Fig. 1), both of which were mesotidal (semidiurnal) and exposed to incoming waves from the SW. Four cross-shore transects were laid out in the two estuaries (Fig. 1); transects A, B and C were located at the mouth of the Maenam Trang and the Maenam Palian, Kantang district, and transect D was located at the confluence of Khong Klak Khan and Khlong Rae, Palian district. All transects exhibited a clear zonation with a mudflat, the pioneer zone dominated by Avicennia spp. and Sonneratia spp. trees and a Rhizophora spp. dominated zone. The tidal amplitude near the field sites is between 1 and $3 \mathrm{~m}$, and wave measurements by Horstman et al. (2012) near transect B and D showed that typical incident wave heights at the mudflat fronting the forest did not exceed $10 \mathrm{~cm}$ with wave periods of 3-5 s during the measurement campaign. During a stormy period wave heights of up to $30 \mathrm{~cm}$ were measured near transect B (Horstman et al., 2012).

The mudflat at transect $\mathrm{B}$ was free from seedlings during the whole monitoring period, whereas transects $A, C$ and D had very few seedlings close to the forest fringe $(<10 \mathrm{~m})$; no new colonization was observed throughout the monitoring season. The transition from mudflat to the pneumatophores 
of the Avicennia/Sonneratia zone was very abrupt. The Rhizophora zone at all transects was characterised by monospecific stands of mature trees with the characteristic stilt roots (see Horstman et al., 2012). Whereas the pioneer zone at transect B was dominated by mature trees (see Horstman et al., 2012), transects A, C and D were dominated by younger trees, smaller than approximately $5 \mathrm{~m}$ in height. Substantial densities of Rhizophora seedlings were only present in gaps and an understory was beside the last plots of transect B and $\mathrm{C}$ where Acanthus spp. was present.

The total length of the transects varied between $200 \mathrm{~m}$ and $500 \mathrm{~m}$ with $8-11$ plots per transect. The plots were closer to each other in the mudflat and pioneer zone than in the Rhizophora zone because of the greater heterogeneity of the forest in the front. A total of 37 marker plates were installed in June 2010, and thereafter revisited bimonthly until April 2011. Measurements were available for 8 months as the plots were allowed to recover for the first 2 months after installation.

Marker plates were made from $40 \times 50 \mathrm{~cm}$ sheets cut from thin wall polycarbonate and buried approximately $30 \mathrm{~cm}$ deep in the mangrove mud along 4 cross-shore transects. After installation the edges of each buried plate were marked with $0.5 \mathrm{~mm}$ thin metal pins (Fig. 3). After 2 months the filled holes were no longer visible and the thin pins did not create any visible scouring. During the surveys the depth of each plate was measured during low tide (each transect on the same day) with a thin rod of fixed length pushed down to the plate at 5 positions. The 4 marker pins allowed the same spots on the plate to be measured each time. Only one person approached the plate to minimize disturbance of the sediment. The change of the plate depth was averaged from the 5 measured points and compared in time and space.

Sediment properties were recorded for all transects on 4 consecutive days in February 2011 near the marker plates, each transect during a single low tide. Mixed surface soil samples were taken $\left(3.2 \mathrm{~cm}\right.$ depth) with a volume of $20 \mathrm{~cm}^{3}$ with a cut-off $60 \mathrm{~mL}$ syringe. Samples were frozen and thereafter taken to the laboratory, analysed for dry weight $(24 \mathrm{~h}$ at $105^{\circ} \mathrm{C}$ ) and organic matter by loss on ignition of the dried samples ( $4 \mathrm{~h}$ at $550^{\circ} \mathrm{C}$ ). Grain size analysis of the dry sieved samples ( $2 \mathrm{~mm}$ mesh size) was performed with a particle size analyser (Malvern Mastersizer). Prior to the grain size analysis the organic matter was removed with $25 \%$ solution of $\mathrm{H}_{2} \mathrm{O}_{2}$.

\section{Results}

\subsection{Critical erosion in the flume}

The critical erosion, defined as the amount of discs at which the seedling would topple when exposed to $8 \mathrm{~cm}$ high waves, was linearly correlated to dry biomass of the Sonneratia seedling (linear model, $N=35, p=0.000$ ) (Fig. 2). The rel-
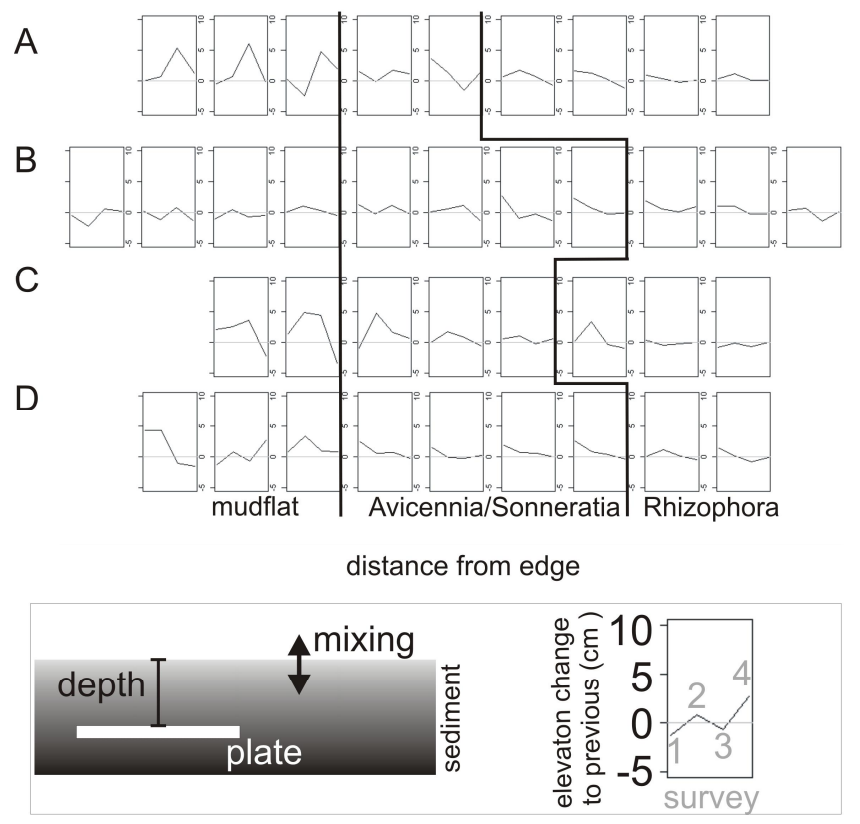

Fig. 3. Change in marker plate depth (positive values: accretion; negative values: erosion) in time for each plot from the mudflat (left) to the back of the forest (right). Five measurements of plate depth were taken in 8 months, leading to 4 points of change in time. The magnitude of change is highest on the mudflat and reduces towards the back of the forest.

evance of this type of flume measurements is emphasized by field observations showing seedlings with exposed roots due to localized erosion (Fig. 2, right photograph of Avicennia spp. seedling).

\subsection{Surface sediment mixing (accretion/erosion) along individual transects}

Accretion events of up to $6 \mathrm{~cm}$ in two months as well as erosion events of up to $3.5 \mathrm{~cm}$ in two months were recorded throughout the campaign (Fig. 3). All transects showed periods of both erosion and accretion. Transects $\mathrm{A}$ and $\mathrm{C}$ displayed the highest accretion events especially on the mudflat and in the Avicennia /Sonneratia zone compared to transects B and D. Erosion events were in general less common than accretion events over the study period, with the exception of the mudflat of transect B. For all transects, very little mixing (erosion or accretion) occurred within the Rhizophora zone.

\subsection{Common pattern of disturbance and sediment parameters along transects}

Surface sediment mixing expressed as standard deviation of plate depth and the surface sediment characteristics (i.e. median grain size and the soil organic matter content) were pooled for all transects and separated into zones to find common patterns. The standard deviation of the plate depth 
a)

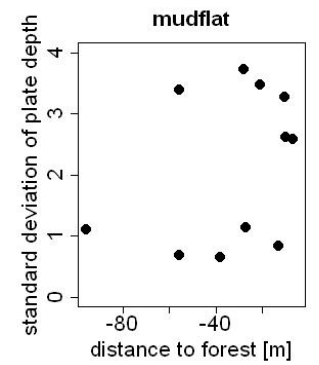

b)

c)
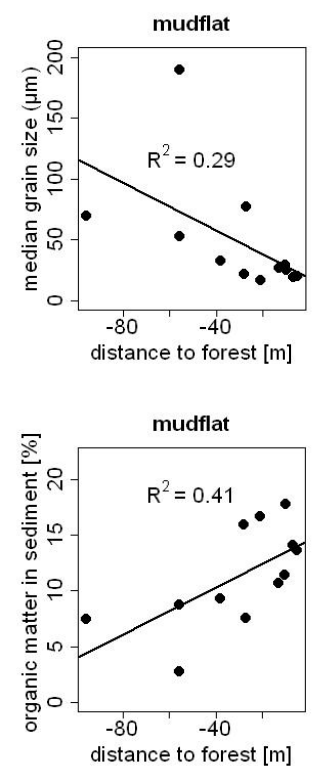

Avicennia/Sonneratia
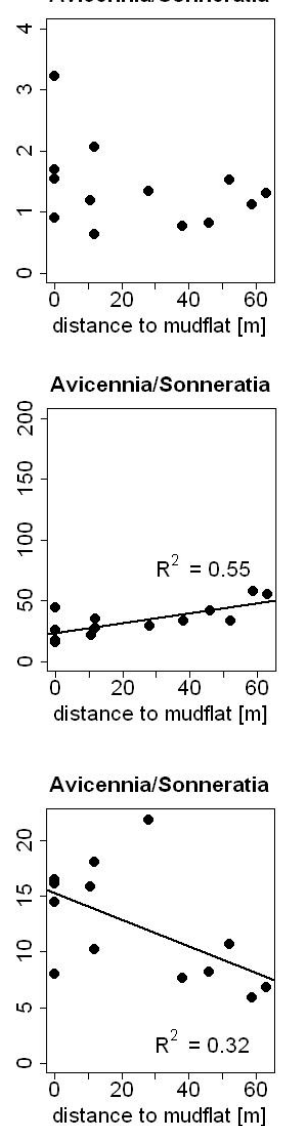
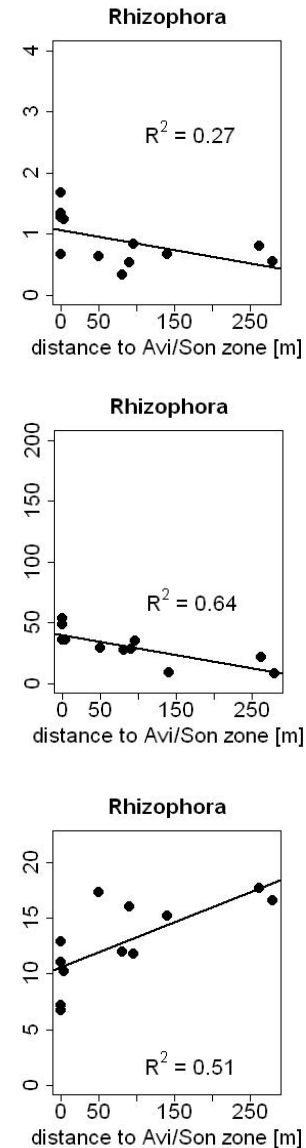

Fig. 4. (a) The standard deviation of the plate depth in time as a measure for magnitude of surface sediment mixing, plotted for all transects per zone and distance from the edge of each zone. While no significant linear relationship is found for the mudflat and the Avicennia/Sonneratia zone, the standard deviation of plate depth decreases with distance in the Rhizophora zone. (b) Median grain size (D50) of the surface sediment samples for all transects per zone. Grain size first decreases towards the forest edge, then increases towards the transition from the Avicennia/Sonneratia to the Rhizophora zone, and thereafter decreases again. The coarsening of the grain sizes in the mangrove fringe could be caused by increased turbulence in the relatively open pioneer zone. (c) Organic matter content of the surface sediment samples for all transects per zone. The organic matter content shows the opposite pattern to that of the grain size; hence finer grains are associated with higher organic matter content.

(5 measurements in 8 months) decreased from the tidal flat towards the back of the forest (Fig. 4a). However, the linear correlation with distance per zone was only significant in the Rhizophora zone (linear model, $N=12, p=0.08$ ). On the mudflat and in the Avicennia /Sonneratia zone no significant trends of plate depth standard deviation with distance were found.

The median grain size of the surface layer (Fig. 4b) decreased with distance towards the forest fringe (linear model, $N=12, p=0.07)$ and increased with distance in the pioneer zone (linear model, $N=13, p=0.004$ ), followed by a decrease in the Rhizophora zone (linear model, $N=12$, $p=0.002)$. Organic matter content of the sediment showed the opposite pattern (Fig. 4c), i.e. a significant increase up to around $15 \%$ on the mudflat (linear model, $N=12$, $p=0.03$ ), a decrease in the Avicennia /Sonneratia zone (lin- ear model, $N=13, p=0.04$ ) and again an increase from $10 \%$ towards $20 \%$ in the Rhizophora zone (linear model, $N=12, p=0.0006)$.

\section{Discussion}

Our results highlight the importance of sediment dynamics as an important driver controlling pioneer-seedling establishment. Young Sonneratia alba seedlings were very sensitive to sediment erosion of $>1-3 \mathrm{~cm}$ while exposed to small waves in a flume. Field surveys revealed that typical sediment dynamics along cross-shore transects in Thai mangroves consistently exceeded the failure threshold for young seedlings on the mudflat and at the forest fringe. Combining the present results with other studies examining the effect of physical disturbance (i.e. fluid motion, erosion, sedimentation) at 


\begin{tabular}{|c|c|c|c|c|}
\hline $\begin{array}{l}\text { seedling } \\
\text { failure: }\end{array}$ & dislodgement & toppling & burial & \\
\hline & $\vec{\rightarrow}$ & $\underset{\square}{\rightrightarrows}$ & & 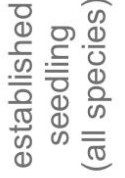 \\
\hline & $\vec{\overrightarrow{ }}$ & can not topple & & 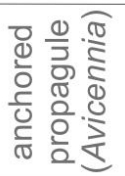 \\
\hline $\begin{array}{l}\text { physical } \\
\text { disturbance: }\end{array}$ & $\begin{array}{l}\text { fluid motion } \\
\text { +erosion } \\
\text { (Balke et al. 2011) }\end{array}$ & $\begin{array}{c}\text { erosion } \\
\text { + fluid motion } \\
\text { (fresent study) } \\
\text { (Balke et al. 2013) }\end{array}$ & $\begin{array}{l}\text { sedimentation } \\
\text { (e.g. Terrados et al. } 1997 \\
\text { Thampanana et al. } 2002 \\
\text { Balke et al. 2013) }\end{array}$ & \\
\hline
\end{tabular}

Fig. 5. Summary of type of seedling failure related to physical disturbance processes comparing effects on just anchored propagules of Avicennia spp. (based on Balke et al., 2011) with established pioneer seedlings (Avicennia spp. and Sonneratia spp.), based on this study and cited literature. Dislodgement occurs due to hydrodynamic drag forces and is especially relevant to recently anchored (viviparous) propagules (here Avicennia spp.) with short roots. Erosion around the roots can increase the susceptibility to dislodgement. Bigger seedlings facing erosion will fail before they get dislodged as remaining roots in the soil are not strong enough to support the seedling to stand upright, resulting in toppling failure. Fluid motion exerts a force on the seedling, decreasing the resistance to toppling (i.e. wave in flume study). New layers of sediment can get deposited and smother established seedlings and anchored propagules or entirely bury them.

various stages of the seedling development of common pioneer species, we present an overview of the failure mechanisms, and link them to the responsible processes in the intertidal environment (Fig. 5).

When the mudflat is inundated during high tide, drag forces by water movement at the bed can dislodge recently anchored mangrove propagules (Balke et al., 2011); however with longer roots, higher drag forces by waves and currents can be resisted (Fig. 5). As the roots anchor the propagule in the sediment, erosion around the roots will reduce the stability against hydrodynamic drag forces (Fig. 5; Balke et al., 2011). Dislodged propagules of Avicennia spp. can strand again and produce new roots several times (Osborne and Berjak, 1997). In contrast, as Sonneratia spp. are not viviparous; they most likely have a single anchoring opportunity. Toppling occurs when seedlings are anchored deep enough to escape dislodgement, but their architecture is not strong enough to support the seedling against surface sediment mixing (Fig. 5). Our results demonstrate that young Sonneratia alba seedlings are unable to withstand erosion events of $>1-3 \mathrm{~cm}$ while exposed to wave action and can gain stability against toppling over time with increasing biomass (Fig. 2). The critical erosion thresholds of $>1-3 \mathrm{~cm}$ are in the range of erosion events that were observed in the field over a 2 month period. Sediment transport can also lead to burial of plants (Fig. 5); this has been experimentally studied in the field for example by applying sediment around mangrove seedlings (Terrados et al., 1997; Thampanya et al., 2002). Present field data with sedimentation of up to $6 \mathrm{~cm}$ in 2 months exceed suggested burial thresholds of $4 \mathrm{~cm}$ for Rhizophora apiculata seedlings (Terrados et al., 1997). Compared to sudden sediment disturbance events, a more gradual sequence of cumulative erosion and accretion events can be less damaging and feed back to the stability of the seedling by altered shoot/ root ratios (Balke et al., 2013).

High-frequency measurements of bed level change and sediment mixing are generally scarce for mangroves, as most data on sediment dynamics in mangroves are collected and interpreted for long-term averaged trends (decades rather than months) with often limited spatial coverage (e.g. core dating, sedimentation-erosion table). This is because the main research interest on sediment dynamics is predominantly focused on long-term accretion rates to see whether mangroves can keep up with sea-level rise (see e.g. Woodroffe, 1995; Lovelock et al., 2011; McKee, 2011; Webb et al., 2013). However our results clearly demonstrate the importance of frequent measurements of sediment dynamics (i.e. accretion/erosion), which is necessary to infer seedling establishment and survival probabilities.

The highest magnitude of sediment mixing was found on the tidal flat and at the forest fringe. This gradient agrees with Saad et al. (1999) and van Santen et al. (2007), who found decreasing accretion rates with distance towards the back of the forest. Due to the relatively short time of this study no seasonal variation could be found; however, it might be expected that during the rainy season more sediment would be available for accretion (but also subsequent resuspension) compared to the dry season (Saad et al., 1999). Hydrodynamic 
energy is dissipated through the above-ground structure of the mangroves (Mazda et al., 2006), and hence materials that settle in the upper intertidal Rhizophora zone are rarely resuspended (van Santen et al., 2007; Alongi, 2009). The present data confirms that the back of the mangrove is a zone with minimal sediment disturbance, as standard deviation of plate depth in the Rhizophora zone was below $1 \mathrm{~cm}$ when passing the transition from the pioneer zone (Fig. 4a). This suggests that sediment disturbance by mixing is not a limiting process in the Rhizophora zone at these field sites, and should only be accounted for in the Avicennia/Sonneratia zone.

Attenuation of hydrodynamic energy and hence attenuation of sediment disturbance or drag forces which can dislodge recently anchored propagules of Avicennia alba (Balke et al., 2011) can be deducted from a gradient in grain size from the tidal flat towards the back of the mangrove; lower energetic conditions favour the settling of finer particles. A gradient in grain sizes (from coarse to fine) from high-energy to low-energy conditions (waves, currents) is common on tidal flats due to decreasing water depth and hence decreasing transport capacity (Quartel et al., 2007). With the presence of vegetation adding roughness, sediment transport capacity is further reduced and only the finest particles reach the upper intertidal zone (or "back mangroves/saltmarsh") (Saad et al., 1999; Quartel et al., 2007; van Santen et al., 2007; Yang et al., 2008; Anthony, 2004). Whereas we found a decrease in grain size of the surface layer with distance in the back of the forest and on the mudflat, a significant increase in grain size with distance from the forest edge was observed (Fig. 4b) in the pioneer zone occupied by Avicennia spp. and Sonneratia spp. trees. Moreover a reduction in deposited organic material was observed at the transition from the rather open Avicennia/Sonneratia zone with their pneumatophores to the denser Rhizophora zone with their stilt roots (Fig. 4c). Both suggest that generally attenuation of hydrodynamic energy is very limited in the open forest fringe at our field sites.

Wave height and vegetation density measurements were carried out close to transect $\mathrm{B}$ and transect $\mathrm{D}$ during the same field campaign by Horstman et al. (2012) and confirmed the limited energy attenuation at the open forest fringe. This was explained by the combination of a low vegetation density $(<5 \%$, above $10 \mathrm{~cm})$ above the dense pneumatophores $(17-23 \%$, at $5 \mathrm{~cm})$, with inundation heights of up to $2 \mathrm{~m}$ (Horstman et al., 2012). The vegetation density only changes in the Rhizophora zone, where water levels do not exceed stilt-root heights, contributing to the attenuation of hydrodynamic energy (Horstman et al., 2012). Literature on vegetation-hydrodynamics interactions suggests that an abrupt change from mudflat to vegetation cover can induce turbulence (Nepf, 1999), which reduces settling of fine particles and can cause resuspension of deposited material, for example at the edge of mudflat and salt marsh vegetation (Neumeier, 2007; Widdows, 2008). Within this context, the most likely explanation for the coarser sediment at the man- grove edge is an increased turbulence within the open pioneer zone, thus keeping fine sediments in suspension and resulting in an initial increase in grain size. These sediment data suggest that within the open forest fringe at our field sites, occupied by Avicennia and Sonneratia, hydrodynamic energy is not sufficiently reduced to facilitate settling and anchorage of propagules (cf. Balke et al., 2011).

The observed sediment mixing depth in the field, in combination with the flume experiment on sediment erosion and current literature on seedling burial, leads to the inference that mangrove pioneer seedling establishment and survival depends on the timing of the sediment dynamics relative to the development of the seedling (cf. Balke et al., 2013). Sediment dynamics are event driven and may occur at very short timescales, e.g. during a series of a few high tides or a storm event, in general much shorter than the 2-month monitoring interval applied in this study. Hence, seedlings that establish in a disturbance-free period (i.e. window of opportunity, cf. Balke et al., 2011) might show high survival rates, whereas one storm event while the seedings are still small may wipe out the majority of the recruits and reduce overall establishment success significantly. These severe disturbance events are irregular and therefore difficult to capture unless highfrequency monitoring is applied.

Ecological restoration of mangroves (i.e. mangrove restoration by means of re-creating the suitable environmental conditions; cf. Lewis III, 2005) is suggested to be more sustainable and often more successful than planting of mangroves (commonly non-pioneer species) on often unsuitable tidal flats. Restoring the conditions (mainly elevation and hence tidal inundation) allows seedlings of mangrove pioneers to establish naturally if dispersal is not limited (Lewis III, 2005, reviewed in Bosire et al., 2008). However, physical disturbance can limit restoration success in planted and ecologically restored mangroves if exposure to waves and/or currents is too high. This physical disturbance of the sediment by hydrodynamic energy is a natural and highly stochastic process (Fig. 3) which may cause failure of seedlings (Fig. 2) including within the forest fringe, depending on the magnitude of the disturbance and the biomass of the seedling (Fig. 5). The variability of the physical coastal environment and temporal matching with the biota are most likely key mechanisms explaining seedling establishment success and failure on exposed tidal flats and mangrove fringes. The present study sets an example on how one might approach further research on short-term sediment-disturbance dynamics in mangroves, as well as their translation to restoration practice. Understanding mangroves as bio-geomorphic ecosystems is an important step towards sustainable management of this valuable and threatened ecosystem.

Acknowledgements. Research was conducted under NRCT permit number 2565 in Thailand and under Singapore NParks permit number NP/RP936-1 in Singapore. The authors gratefully acknowledge 
the support \& contributions of the Singapore-Delft Water Alliance (SDWA) Marine 3 research programme, grants R303-001-001272 and R-264-001-024-414. We acknowledge Demis Galli for help in the flume and field study as well as Sit Beng Chiat, Krishna Sanmugam and Shaja Khan for technical support in the NUS wave flume. Eva van den Elzen, Siti M. Yaakub and many others are acknowledged for their support during the fieldwork. Marjolein Dohmen-Janssen is acknowledged for comments on earlier versions of the manuscript. The analytical laboratory of the NIOZ in Yerseke is acknowledged for the grain size analysis.

Edited by: B. Satyanarayana

\section{References}

Alongi, D. M.: Mangrove forests: Resilience, protection from tsunamis, and responses to global climate change, Estuar. Coast. Shelf S., 76, 1-13, 2008.

Alongi, D. M.: The Energetics of Mangrove Forests, Springer, Dordrecht, the Netherlands, 2009.

Anthony, E. J.: Sediment dynamics and morphological stability of estuarine mangrove swamps in Sherbro Bay, West Africa, Mar. Geol., 208, 207-24, 2004.

Anthony, E. J., Gardel, A., Gratiot, N., Proisy, C., Allison, M. A., Dolique, F., and Fromard, F.: The Amazon-influenced muddy coast of South America: A review of mud-bank-shoreline interactions, Earth-Sci. Rev. ,103, 99-121, 2010.

Ashford, A. E. and Allaway, W. G.: There is a continuum of gas space in young plants of Avicennia marina, Hydrobiologia, 295, 5-11, 1995.

Balke, T., Bouma, T. J., Horstman, E. M., Webb, E. L., Erftemeijer, P. L. A., and Herman, P. M. J.: Windows of opportunity: thresholds to mangrove seedling establishment on tidal flats, Mar. Ecol.-Prog. Ser., 440, 1-9, 2011.

Balke, T., Webb, E. L., van den Elzen, E., Galli, D., Herman, P. M. J., and Bouma, T. J.: Seedling establishment in a dynamic sedimentary environment: a conceptual framework using mangroves, J. Appl. Ecol., 50, 740-747, 2013.

Ball, M. C. and Pidsley, S. M.: Growth Responses to Salinity in Relation to Distribution of Two Mangrove Species, Sonneratia alba and S. lanceolata, in Northern Australia, Funct. Ecol., 9, 7785, 1995.

Bosire, J. O., Dahdouh-Guebas F., Walton, M., Crona, B. I., Lewis III, R. R., Field, C., Kairo, J. G., and Koedam, N.: Functionality of restored mangroves: A review, Aquat. Bot., 89, 251-259, 2008.

Ellison, J. C.: Impacts of Sediment Burial on Mangroves, Mar. Pollut. Bull., 37, 420-426, 1998.

FAO (Food and Agriculture Organization): The world's mangroves 1950-2005. FAO Forestry Papers, 153 pp., 2007.

Friess, D. A., Krauss, K. W., Horstman, E. M., Balke, T., Bouma, T. J., Galli, D., and Webb, E. L.: Are all intertidal wetlands created equal? Bottlenecks, thresholds and knowledge gaps to mangrove and saltmarsh ecosystems, Biol. Rev., 87, 346-366, 2012.

Hines E. M.: Dugong (Dugong Dugong) abundance along the Andaman coast of Thailand, Mar. Mammal Sci., 21, 536-549, 2005.

Horstman, E. M., Dohmen-Janssen, C. M., Narra, P., Van den Berg, N. J. F., Siemerink, M., Balke, T., Bouma, T. J., and Hulscher, S. J. M. H.: Wave attenuation in mangrove forests; field data ob- tained in Trang, Thailand, in: Proceedings of 33rd International Conference on Coastal Engineering (ICCE), edited by: McKeeSmith, J. and Lynett, P., Santander, Spain, 1-6 July 2012.

Krauss, K. W., Lovelock, C. E., McKee, K. L., Lopéz-Hoffman, L., Ewe, S. M. L., and Sousa, W. P.: Environmental drivers in mangrove establishment and early development: A review, Aquat. Bot., 89, 105-127, 2008.

Lewis III, R. R.: Ecological engineering for successful management and restoration of mangrove forests, Ecol. Eng., 24, 403-418, 2005.

Lovelock, C. E., Sorrell, B. K., Hancock, N., Hua, Q., and Swales, A.: Mangrove Forest and Soil Development on a Rapidly Accreting Shore in New Zealand, Ecosystems, 13, 437-451, 2010.

Lovelock, C. E., Bennion, V., Grinham, A., and Cahoon, D. R.: The Role of Surface and Subsurface Processes in Keeping Pace with Sea Level Rise in Intertidal Wetlands of Moreton Bay, Queensland, Australia, Ecosystems, 14, 745-757, 2011.

Mazda, Y., Magi, M., Ikeda, Y., Kurokawa, T., and Asano, T.: Wave reduction in a mangrove forest dominated by Sonneratia sp., Wetl. Ecol. Manag., 14, 365-378, 2006.

McKee, K. L.: Seedling recruitment patterns in a Belizean mangrove forest: effects of establishment ability and physicochemical factors, Oecologia 101, 448-460, 1995.

McKee, K. L.: Biophysical controls on accretion and elevation change in Caribbean mangrove ecosystems, Estuar. Coast. Shelf S., 91, 475-483, 2011.

Minchinton, T. E. and Dalby-Ball, M: Frugivory by insects on mangrove propagules: effects on the early life history of Avicennia marina, Oecologia, 129, 243-252, 2001.

Nepf, H. M.: Drag, turbulence, and diffusion in flow through emergent vegetation, Water Resour. Res., 35, 479-489, 1999.

Neumeier, U.: Velocity and turbulence variations at the edge of salt marshes, Cont. Shelf Res., 27, 1046-1059, 2007.

Osborne, J. and Berjak, P.: The making of mangroves: the remarkable pioneering role played by seeds of Avicennia marina, Endeavour, 21, 143-147, 1997.

Paling, E. I., Kobryn, H. T., and Humphreys, G,: Assessing the extent of mangrove change caused by Cyclone Vance in the eastern Exmouth Gulf, northwestern Australia, Estuar. Coast. Shelf S., 77, 603-613, 2008.

Panapitukkul, N., Duarte, C.M., Thampanya, U., Kheowvongsri, P., Srichai, N., Geertz-Hansen, O., Terrados, J., and Boromthanarath, S.: Mangrove Colonization: Mangrove Progression Over the Growing Pak Phanang (SE Thailand) Mud Flat, Estuar. Coast. Shelf S., 47, 51-61, 1998.

Proisy, C., Gratiot, N., Anthony, E. J., Gardel, A., Fromard, F., and Heuret, P.: Mud bank colonization by opportunistic mangroves: A case study from French Guiana using lidar data, Cont. Shelf Res., 29, 632-41, 2009.

Quartel, S., Kroon, A., Augustinus, P. G. E. F., Van Santen, P., and Tri, N. H.: Wave attenuation in coastal mangroves in the Red River Delta, Vietnam, J. Asian Earth Sci., 29, 576-584, 2007

Saad, S., Husain, M. L., Yaacob, R., and Asano, T.: Sediment accretion and variability of sedimentological characteristics of a tropical estuarine mangrove: Kemaman, Terengganu, Malaysia, Mangroves and Salt Marshes 3, 51-58, 1999.

Smith, T. J., Robblee, M. B., Wanless, H. R., and Doyle, T. W.: Mangroves, Hurricanes, and Lightning Strikes, BioScience, 44, 256-262, 1994. 
Smoak, J. M. and Patchineelam, S. R.: Sediment mixing and accumulation in a mangrove ecosystem: evidence from ${ }^{210} \mathrm{~Pb},{ }^{234} \mathrm{Th}$ and ${ }^{7} \mathrm{Be}$, Mangroves and Salt Marshes, 3, 17-27, 1999.

Swales, A., Bentley, S. J., Lovelock, C. E., and Bell, R. G.: Sediment Processes and Mangrove-Habitat Expansion on a RapidlyPrograding Muddy Coast, New Zealand, in: Proceedings of the sixth International Symposium on Coastal Engineering and Science of Coastal Sediment Process, New Orleans, Louisiana, United States, 13-17 May 2007, 1441-1454, 2007.

Terrados, J., Thampanya, U., Srichai, N., Kheowvongsri, P., GeertzHansen, O., Boromthanarath, S., Panapitukkul, N., and Duarte, C. M.: The Effect of Increased Sediment Accretion on the Survival and Growth of Rhizophora apiculata Seedlings, Estuar. Coast. Shelf S., 45, 697-701, 1997.

Thampanya, U., Vermaat, J. E., and Terrados, J.: The effect of increasing sediment accretion on the seedlings of three common Thai mangrove species, Aquat. Bot., 4, 315-325, 2002.

Thampanya, U., Vermaat, J. E., Sinsakul, S., and Panapitukkul, N.: Coastal erosion and mangrove progradation in Southern Thailand, Estuar. Coast. Shelf S., 68, 75-85, 2006.

Tomlinson, P. B.: The botany of mangroves, Cambridge University Press, Cambridge, UK, 1986.
Van Santen, P., Augustinus, P. G. E. F., Janssen-Stelder, B. M., Quartel, S., and Tri, N. H.: Sedimentation in an estuarine mangrove system, J. Asian Earth Sci., 29, 566-575, 2007.

Webb, E. L., Friess, D. A., Krauss, K. W., Cahoon, D. R., Guntenspergen, G. R., and Phelps, J.: A global standard for monitoring coastal wetland vulnerability to accelerated sea level rise, Nature Climate Change, 3, 458-465, 2013.

Widdows, J., Pope, N. D., and Brinsley, M. D.: Effect of Spartina anglica stems on near-bed hydrodynamics, sediment erodability and morphological changes on an intertidal mudflat, Mar. Ecol.Prog. Ser., 362, 45-57, 2008.

Woodroffe, C. D.: Response of tide dominated mangrove shorelines in Northern Australia to anticipated sea-level rise, Earth Surf. Proc. Land., 20, 65-85, 1995.

Yang, S. L., Li, H., Ysebaert, T., Bouma, T. J., Zhang, W. X., Wang, Y. Y., Li, P., Li, M., and Ding, P. X.: Spatial and temporal variations in sediment grain size in tidal wetlands, Yangtze Delta: On the role of physical and biotic controls, Estuar. Coast. Shelf S., 77, 657-671, 2008. 